\title{
Retraction Note to: Application of GIS real-time monitoring system in the ecological impact of marine tourism industry development and marine resource protection
}

\author{
Xinqi Ding ${ }^{1} \cdot$ Fei $^{2 i^{2,3,4}}$
}

Published online: 23 November 2021

(c) Saudi Society for Geosciences 2021

Retraction Note to: Arabian Journal of Geosciences (2021) 14: 878 https://doi.org/10.1007//12517-021-07210-3

The Editor-in-Chief and the Publisher have retracted this article because the content of this article is nonsensical. The peer review process was not carried out in accordance with the Publisher's peer review policy. The authors have not responded to correspondence regarding this retraction.

The original article can be found online at https://doi.org/10.1007/ s12517-021-07210-3.

Fei Li

lifeicas@126.com

Xinqi Ding

Dxq15064561353@163.com

1 College of Business, Yantai Nanshan University, Longkou 265713, Shandong, China

2 Institute of Geographic Sciences and Natural Resources Research, Chinese Academy of Sciences, Beijing 100101, China

3 University of Chinese Academy of Sciences, Beijing 100049, China

4 Innovation Academy for Green Manufacture, Chinese Academy of Sciences, Beijing 100190, China 